DOI: $10.20472 /$ IAC.2019.049.047

\author{
ANDREAS ZEHETNER \\ University of Applied Sciences Upper Austria, Austria
}

DANIELA ZEHETNER

Private Researcher, Austria

\title{
RECRUITMENT MARKETING: DO WE UNDERSTAND WHAT GENERATION Z EXPECTS FROM ITS FUTURE EMPLOYERS?
}

\begin{abstract}
:
The struggle for finding good employees in Austrian companies is in full swing, and it rests as a big problem on the desks of recruitment marketers and HR departments. Aside from a general shortage due to demographic developments, a new generation of future employees (the ' $Z$ ' generation) is growing up, and will be present on the labour markets in a very short time. These young people have been raised under completely different (technological, economic, and social) conditions and, in turn, have different expectations of their future job life and employers. Experience as well as literature on employment related expectations, motivation, and behaviours of Gen Z representatives is scarce, which makes it hard for companies to shape their job offerings in an efficient and effective way, matching the demands of this group.
\end{abstract}

In order to contribute to a better understanding of this phenomenon, a large-scale mixed-method research was undertaken, six focus groups with 43 participants and 550 personal interviews with pupils and young students were conducted in Austria. The motivation was to identify and categorize criteria, which might distinguish an 'attractive from an average job' in the eyes of a Gen $X$ candidate. Factor analysis methods were employed to reveal the categories that matter for this group.

The findings suggest that the most important criteria for Gen X members are predominantly "social", namely team spirit, working atmosphere, job-life-integration. "Factual" arguments like salary, job security, career advancement and task diversity only play a secondary role. The HOW is more important than the WHAT. A paradigm shift seems to gain momentum: Currently, most current job descriptions emphasize "what" statements: "What are your tasks?"; "what are opportunities for development?"; or "what is expected from you?". However, Generation Z seems to be much more concerned about the "HOW": "How does it feel to work here?"; "how does my team function?"; "How will my working day in this company look like?"; or " how diversified and exciting is my job?" Salary, job security and a financially stable company are still relevant, but they are not in the foreground. In addition, trends such as home office or high tech equipment of the office appeared to be not too catchy.

The paper ends with recommendations for HR-representatives, including a better visualization of team spirit and working atmosphere, raising awareness for the social aspect of work, and establishing tangible elements of "how it is to work in that company".

\section{Keywords:}

Employer Branding; Recruitment marketing; Generation Z; 
JEL Classification: M31, M51, J62 